TITLE: A 'dyadic dance': Pain catastrophizing moderates the daily relationships between parent mood and protective responses and child chronic pain

Alexandra Neville, $\mathrm{MSc}^{1}$, Yannick Griep, $\mathrm{PhD}^{1,2}$, Tonya M. Palermo, $\mathrm{PhD}^{3}$, Tine Vervoort, $\mathrm{PhD}^{4}$, Fiona Schulte, $\mathrm{PhD}^{5}$, Keith Owen Yeates, $\mathrm{PhD}^{1}$, Janice E. Sumpton, BScPhm ${ }^{6}$, Richelle Mychasiuk, $\mathrm{PhD}^{7}$, Melanie Noel, $\mathrm{PhD}^{1}$

${ }^{1}$ Department of Psychology, University of Calgary

${ }^{2}$ Division of Epidemiology, Stress Research Institute, Stockholm University, Stockholm, Sweden

${ }^{3}$ Departments of Anesthesiology \& Pain Medicine, Pediatrics, and Psychiatry, University of Washington, Seattle, WA, USA

${ }^{4}$ Department of Experimental-Clinical and Health Psychology, Ghent University, Ghent, Belgium

${ }^{5}$ Department of Oncology, Division of Psychosocial Oncology, Cumming School of Medicine, University of Calgary

${ }^{6}$ Department of Pharmacy, Victoria Hospital, London Health Sciences Centre, London, Ontario, Canada

${ }^{7}$ Department of Neuroscience, Monash University, Melbourne, Australia

Manuscript Pages: 34

Tables: 6

Figures: 4

Corresponding Author:

Melanie Noel, PhD

Department of Psychology, The University of Calgary and Alberta Children's Hospital Research Institute; 2500 University Dr. N.W. Calgary, AB, T2N 1N4, Canada

Telephone: 403-477-1162

Email: Melanie.Noel@ucalgary.ca 


\begin{abstract}
Children's experience of chronic pain is influenced by the psychological and behavioural responses of their parents. However, the vast majority of research has been cross-sectional, precluding examination of how these dynamic relationships unfold over time. This study used a micro-longitudinal design to examine the daily relationships between parent mood and protective responses and child chronic pain. We also examined the moderating roles of child and parent pain catastrophizing to determine how the affective-motivational context may alter the influence of parent factors. Participants included 95 youth with idiopathic chronic pain $\left(M_{\text {age }}=14.08\right.$; $71.6 \%$ female) and their parents. At baseline, parents and youth reported on their catastrophic thinking about child pain. For 7 consecutive days, parents completed daily assessments of their mood and protective responses, while youth completed assessments of their pain intensity, unpleasantness, and interference. Multi-level path analyses were conducted. At a daily level, greater parent protectiveness significantly predicted higher youth pain unpleasantness, interference, and intensity; more negative parent mood significantly predicted higher youth pain intensity and unpleasantness. Higher baseline youth pain catastrophizing predicted a stronger daily association between parent mood and youth pain unpleasantness and intensity. Higher baseline parent pain catastrophizing predicted a weaker daily association between parent protectiveness and youth pain interference. Findings suggest that parent mood and protective responses are dynamic, daily predictors of child pain. Findings also underscore the importance of addressing parents' daily mental health and protectiveness, among youth with chronic pain, and suggest different intervention targets depending on levels of child and parent catastrophizing.
\end{abstract}




\section{A 'dyadic dance': Pain catastrophizing moderates the daily relationships between parent mood and protective responses and child chronic pain}

The interpersonal context is critical in conceptual models of pediatric chronic pain [8; 13]. Palermo and Chambers' [34] framework of parent and family factors in children's chronic pain posits that individual parent factors (protectiveness) should be considered within the context of dyadic relationships (parent-child interactions) and the family environment, emphasizing reciprocal relationships between pain, parent, and youth factors. Parent and youth pain catastrophizing predicts worse youth chronic pain $[9 ; 14 ; 48]$. Parents who catastrophize about their child's pain are more likely to experience heightened levels of distress, which contribute to greater protective responses (parental reinforcement of and attention to pain behaviours) [3], and increased child pain intensity and disability $[15 ; 24 ; 41]$. Among healthy children, pain catastrophizing has been shown to moderate the impact of parental presence on pain expression, such that children low in catastrophizing express more pain when a parent is present [46]. Parent protective responses are associated with maladaptive child outcomes, including poor school attendance and functioning [25], somatic symptoms, and disability [5; 20]. However, findings are equivocal as, in several recent studies, parent protectiveness assessed at one point in time (requiring parents to average their responses over 7 days) was not associated with child chronic pain outcomes $[21 ; 39 ; 44]$. The majority of studies to date have been limited by reliance on cross-sectional, retrospective questionnaire data.

The dynamic relationships between parent mood, parent behavioural responses, and youth chronic pain can arguably best be understood using daily assessments, which capture dayto-day responses in relation to children's pain complaints as they unfold in their naturalistic environments. Rather than rely on global retrospective reports of pain and behaviour, daily 
assessments reduce recall bias and better capture change over time [42]. Connelly and colleagues [7] recently showed that parent daily responses to child pain vary more within versus between caregivers. Parent protective responses predicted a subsequent increase in child pain intensity and interference, and parents engaged in more protective responses when their child reported more pain [7]. Conversely, parents engaged in less protective responses when they reported higher positive affect [7]. Given that maladaptive parental behaviours and high parental distress have been found to exacerbate child chronic pain $[3 ; 15 ; 24 ; 41]$ and impede treatment response [21], parental factors are critical to investigate. Yet, daily relationships between parent protectiveness, mood, and youth pain have not been examined among youth with idiopathic chronic pain. Moreover, as posited by Palermo and Chambers [34], individual differences (e.g., coping, perceived threat) may moderate the relationship between parent/family factors and child pain, but have rarely been examined in this context.

The current study examined the daily relationships among parent psychological (mood) and behavioural (protectiveness) factors and the pain experiences of youth with idiopathic chronic pain. We hypothesized that 1) more negative parent mood and increased parent protective responses would be associated with increased youth pain intensity, interference, and unpleasantness on a daily basis, and 2) higher parent and youth pain catastrophizing assessed at baseline would predict stronger daily associations between parent protectiveness/mood and youth pain.

\section{Methods}

\section{Participants}

The current study is part of the Pain and Mental Health in Youth study (PATH), a larger longitudinal research project investigating internalizing mental health disorders in youth with 
chronic pain. The aims of the broader study were to examine cognitive, behavioural, neurobiological, and social factors underlying co-occurring mental health symptoms and chronic pain. The aims of the current study were unique and specific to examining the daily parent-child interactions, data from which have not yet been published. To date, one qualitative paper based on 20 families from the larger PATH study has been published that examined diagnostic uncertainty of parents and youth [31].

Two hundred fifteen youth, and one of their parents, were recruited from a tertiary-level pediatric chronic pain program in Western Canada. Of those, 72 declined participation due to not being interested or being too busy to participate, and 43 were not eligible ( 23 reported no longer having chronic pain, 17 did not meet age criteria, 2 reported an underlying disease, 1 reported diagnosis of a developmental disorder). Thus, 100 youth and one of their parents consented to participate in the study; however, five parent-youth dyads withdrew prior to completing any assessments. The current sample includes 95 youth with chronic pain $(71.6 \%$ female, $M_{\text {age }}=14.08$, Range $=10-18$ years $)$ and one of their parents ( $94.5 \%$ mothers $)$. Youth were eligible for the study if they were between 10-18 years of age, were identified as having chronic pain (i.e., pain $\geq 3$ months) without an underlying disease (e.g., juvenile arthritis or cancer) by a health care provider in the Abdominal, Complex Pain or Headache clinics. Exclusion criteria for both the youth and parent included being unable to read/speak English, diagnosis of a severe cognitive disability, developmental disorder, schizophrenia spectrum or other psychotic disorders, or inability to access the internet.

\section{Procedure}

All study procedures were approved by the institutional health Research Ethics Board. Parents were first approached by a member of the pain clinic staff for permission to be contacted 
by the research team. Parents and youth were then contacted by a member of the research team to assess eligibility, answer questions about the study, and obtain informed consent. Parents and youth consented using an online consent form and completed baseline questionnaires using Research Electronic Data Capture (REDCap), a secure online data collection tool [16]. Parents and youth completed psychometrically sound self-report baseline measures of pain catastrophizing. Youth also completed baseline measures about their pain characteristics. Then, for seven consecutive days, youth completed daily electronic assessments of their pain intensity, pain interference, and pain unpleasantness through REDCap using their own web-enabled device. Electronic daily diaries have been demonstrated to be feasible among youth with chronic pain, as well as to increase compliance and accuracy of daily pain reporting compared to paper formats [36]. Parents completed daily assessments of their own mood and protective responses to their child's pain. Similar to Connelly and colleagues [7], this provided a measure of daily behaviour in the more naturalistic setting of the home. Daily assessments were modelled after previous research [40]. Secure links to REDCap surveys were emailed or texted (depending on parent and youth preference) separately to parents and youth at $6 \mathrm{pm}$ each evening. Parents and youth each received a $\$ 25$ gift card for their participation.

\section{Baseline Measures}

\section{Demographic Characteristics}

Parents reported on their own and their child's sex, ethnicity, age, as well as household income.

\section{Child Pain Characteristics}

Youth completed the valid and reliable Pain Questionnaire [37]. Youth reported on the location of their body where they experience the most pain as well as how long their pain 
problem has been present in years and months. Pain frequency in the past seven days was rated on a 5-point Likert scale ranging from "not at all" to "daily." Youth reported their average pain intensity in the past seven days using a validated 11 -point numeric rating scale $(0=$ "no pain", 10 $=$ "worst pain possible") [4; 50]. Youth reported their average pain unpleasantness using a 5point Likert scale from "Not at all" to "Very much" [29; 36].

\section{Youth and Parent Pain Catastrophizing}

The Pain Catastrophizing Scale-Child version (PCS-C) [9] and the Pain Catastrophizing Scale-Parent version (PCS-P) [14] were used to assess catastrophic thoughts about child pain. The PCS-P and PCS-C capture trait catastrophizing. Each scale contains 13 items rated on a 5point Likert scale (anchors $0=$ "not at all," $4=$ "extremely"). Items are summed to produce a total score. Lower scores indicate a lower level of pain catastrophizing. The PCS-C describes what a child might feel and think when they experience pain (e.g., "When I am in pain, I become afraid that the pain will get worse"). The PCS-P assesses how a parent might feel when his/her child is in pain (e.g., "When my child is in pain, I become afraid that the pain will get worse"). The PCS-C and the PCS-P have been previously validated in pediatric populations with chronic pain and their parents and have demonstrated good validity and reliability [9; 14]. Internal consistency for the baseline measure of youth pain catastrophizing $(\alpha=.94)$ and parent pain catastrophizing $(\alpha=.92)$ was excellent in this sample. Parent and child trait catastrophizing have been linked to poorer child functioning and increased pain $[9 ; 15 ; 25 ; 26 ; 38]$.

\section{Daily Measures}

Parent Protective Responses to Youth pain

Parents reported on their responses to their child's pain using the Protect scale of the Adult Responses to Children's Symptoms (ARCS) [45], once daily for 7 days. Using a 5-point 
scale ranging from "never" to "always," parents reported on the frequency with which they engaged in various behaviours (e.g., "Give your child special privileges") when their child had pain that day. The ARCS has been shown to be reliable and valid in samples of youth with chronic pain [32] and has been previously used in an electronic daily diary format with youth with Juvenile Idiopathic Arthritis [7]. Based on recent research [33] examining the factorial validity of the ARCS separately in caregivers of children versus adolescents with chronic pain, the current study used this newly derived ARCS scoring. Responses are averaged to provide a protect score, with higher scores indicative of greater parent protective behaviours. Internal consistencies for the ARCS protect scale reported at each time point of daily measures ranged from .68 to .90 for caregivers of children (mean $\alpha=.83$ ), and .81 to .88 for caregivers of adolescents (mean $\alpha=.84)$.

\section{Parent Mood}

Parent mood was measured using a single item 11-point numeric rating scale (NRS): Please rate your mood at the time you woke up $(0=$ "extremely negative mood" to $10=$ “extremely positive mood”). Single item NRS scales have been used to assess mood in prior studies among adults [2].

\section{Youth Pain Experiences: Pain Interference, Intensity and Unpleasantness}

Pain interference was assessed using the Pain Interference Subscale of the PatientReported Outcomes Measurement Information System (PROMIS) Pediatric Profile-25 [18]. The four item subscale was rated using a 5-point Likert scale from "never" to "almost always". The response format was modified to ask youth to respond to these items based on "Today". A total score of pain interference is obtained by summing responses. This total is subsequently transformed into standardized T-scores used for analyses. Internal consistencies for pain 
interference reported at each time point of daily measures ranged from .79 to .90 (mean $\alpha=.85$ ). Youth were also asked to rate their pain intensity each day by responding to a single item: "How much pain did you have today?". This item was rated using an 11-point numeric rating scale $(0=$ "no pain" to $10=$ "worst pain possible")[4;50], which has been used in daily diary format with youth with chronic pain [22]. The pain unpleasantness item, as described above, was adjusted to reflect a daily measurement: "How much has your pain bothered you today?". This item was rated on a 5-point Likert scale from "not at all" to "very much"and has been used in a daily diary format [36].

\section{Statistical Analyses}

Overall, daily variables had a range of $3.20 \%-27.40 \%$ missing data across all 7 days (youth pain intensity $=5.30 \%$; youth pain interference $=18.20 \%$; youth pain unpleasantness $=$ $18.30 \%$; parent $\operatorname{mood}=3.20 \%$; parent protectiveness $=27.40 \%$ ).

Statistical analyses were conducted using Mplus version 7.1 [30] and the Statistical Package for the Social Sciences (SPSS) Version 24 (Armonk, NY). Ninety-five dyads completed up to seven repeated measurements, thereby exceeding the basic sample size recommendations of 30 units at the Level 2 of analysis for adequate power and non-biased estimates [27]. At the Level 1 of analysis we included 644 observations ( 95 dyads $\mathrm{x}$ a maximum of 7 completed diaries), which exceeds the recommended Level 1 sample size to achieve accurate estimations of standard errors of fixed effects [27].

To address our hypothesis that higher parent and youth pain catastrophizing assessed at baseline would predict stronger daily associations between parent protective behaviours-youth pain and parent mood-youth pain, multilevel modeling was used to account for repeated measurements (Level 1) nested within each parent-youth dyad (Level 2). This is considered the 
most appropriate analysis for daily data [1]. Intra-class correlation coefficients (ICC) of all repeated measure variables (i.e., pain intensity, pain interference, pain unpleasantness, parent mood, and parent protectiveness) were calculated to justify a multilevel modeling approach [17]. ICC values $(.41, .28, .62, .56, .32$ respectively) indicated that a substantial and non-trivial proportion of total variance of these variables was due to within-person differences [28].

Multilevel path analysis is ideal for analyzing complex models because it allows for all outcomes to be correlated at each point in time and it allows for the simultaneous estimate of multiple path coefficients in one overall model [23]. A multilevel path analysis was conducted using Mplus version 7.1 [30], in which a 2-level path model was estimated. Specifically, to investigate the daily associations between predictors and youth outcomes, the between-person (i.e., level 2) x within-person (i.e., level 1) part of the 2-level path model was specified [27]. In other words, the level-1 variables (i.e., youth pain intensity, youth pain unpleasantness, youth pain interference, parent mood, and parent protectiveness) were decomposed into withinand between-person level relationships [51]. In this part of the model, the daily associations between parent protectiveness and youth pain intensity, youth pain unpleasantness, and youth pain interference were predicted. Then, the associations between parent mood and youth pain intensity, youth pain unpleasantness, and youth pain interference within the same day were predicted. To investigate the direct effect of stable parent/youth predictors (i.e., pain catastrophizing) on youth pain outcomes, the between-person part of the 2-level path model, reflecting the direct relationship of parent pain catastrophizing and youth pain catastrophizing on youth pain intensity, youth pain unpleasantness, and youth pain interference, was specified. In addition, the cross-level interaction effect of parent pain catastrophizing on the daily association between parent protectiveness and youth pain intensity, youth pain unpleasantness, 
and youth pain interference was specified. Then, the cross-level interaction effect of parent pain catastrophizing on the daily association between parent mood and youth pain intensity, youth pain unpleasantness, and youth pain interference was specified. Next, the cross-level interaction effect of youth pain catastrophizing on the daily association between parent protectiveness and youth pain intensity, youth pain unpleasantness, and youth pain interference was specified. Lastly, the cross-level interaction effect of youth pain catastrophizing on the daily association between parent mood and youth pain intensity, youth pain unpleasantness, and youth pain interference was specified. Maximum likelihood was used with robust standard errors as an estimator in the path analysis. Parameters were standardized estimates to facilitate the interpretation of our results [17].

We included a single main effect predictor at level 1 (daily observations) and included a single main effect predictor at level 2 (parent-youth dyad) which is manifested in the reduced form equation as a cross-level interaction. The level 1 equation is as followed:

$y_{i j}=\beta_{0 j}+\beta_{1 j} x_{1 i j}+r_{i j}(1)$

Where $x_{1 i j}$ is the observed predictor (parent mood or parent protectiveness) for observation $i$ (a daily observation) nested within group $j$ (a parent-youth dyad), $\beta_{1 j}$ is the regression slope of $y$ (youth pain intensity, youth pain inference, or youth pain unpleasantness) on $x_{1}$ (parent mood or parent protectiveness) within group $j$ (a parent-youth dyad), and $r_{i j}$ is the residual term.

The level 2 equations are as followed:

$\beta_{0 j}=\gamma_{00}+\gamma_{01} \omega_{1 j}+\mu_{0 j}(2)$

$\beta_{1 j}=\gamma_{10}+\gamma_{11} \omega_{1 j}+\mu_{1 j}(3)$ 
Where $\omega_{1 j}$ is the observed predictor for group $j$ (a parent-youth dyad), $\gamma_{00}$ and $\gamma_{10}$ are the fixed intercepts, $\gamma_{01}$ and $\gamma_{11}$ are the fixed regression coefficients for $\omega_{1 j}$ (parent pain catastrophizing or youth pain catastrophizing), and $\mu_{0 j}$ and $\mu_{1 j}$ are the residual terms.

Finally, substituting the level 2 equation into the level 1 equation results in the reduced form equation as followed:

$y_{i j}=\left(\gamma_{00}+\gamma_{10} x_{1 i j}+\gamma_{01} \omega_{1 j}+\gamma_{11} x_{1 i j} \omega_{1 j}\right)+\left(\mu_{0 j}+\mu_{1 j} x_{1 i j}+r_{i j}\right)$

It can be seen that the regression of the level 1 slope on the level 2 covariate results in a cross-level interaction between $x_{1 i j}$ (parent mood or parent protectiveness) and $\omega_{1 j}$ (parent pain catastrophizing or youth pain catastrophizing) with regression coefficient $\gamma_{11}$ (cross-level interaction term between parent mood or parent protectiveness and parent pain catastrophizing or youth pain catastrophizing).

No participants were excluded from analyses. Throughout these analyses, the Full Information Maximum Likelihood (FIML) method was relied on to reduce response bias [10]. When using FIML, missing values (either by not having completed a full wave of data collection or just one item or one scale) are not deleted, replaced, or imputed, but missing data are handled within the analysis. This method allows for all available information to be used to estimate the model. It is also superior to listwise deletion as no information is lost in the estimation of the analysis model. FIML estimates the population parameters that would most likely have produced the estimates from the sample data [6].

Acknowledging the possibility of reverse causation (i.e., that youth pain could drive parent mood and parent responses to their child), we found that our hypothesized models $(\mathrm{BIC}=$ 9299.62 and $\mathrm{BIC}=7300.49$, respectively) consistently fit the data better than the reverse models 
$(\mathrm{BIC}=9984.41$ and $\mathrm{BIC}=7974.44$, respectively) based on Bayesian Information Criterion (BIC) values. Thus, analyses proceeded with the hypothesized models. In line with previously identified covariates in psychosocial studies in pediatric chronic pain [19], youth age and sex were controlled for in all analyses by estimating their association with the outcome variables of interest.

\section{Results}

\section{Descriptive Statistics}

Youth were enrolled from the headache (58\%), complex pain (41\%), or abdominal pain (1\%) clinics. Youth reported experiencing the most pain in their head (63.2\%), muscles and joints (25.3\%), other (23.2\%), stomach (17.9\%), legs (13.7\%), and chest (10.5\%). Youth reported an average pain intensity level in the past week of 5.62 out of $10(S D=1.87)$ and an average pain duration of 3.62 years $(S D=3.36)$. Over half $(52 \%)$ of youth reported that they had experienced pain daily over the past week. Sociodemographic data are presented in Table 1.

Baseline parent and youth pain catastrophizing scores averaged $15.05(S D=9.22)$ and $20.02(S D=12.53)$, respectively. According to empirically-derived clinical reference points among youth with chronic pain [38], 29.7\% of youth reported "high" levels of pain catastrophizing, $36.2 \%$ reported "moderate" levels of pain catastrophizing, and $34.1 \%$ reported "low" levels of pain catastrophizing. Youth age was not significantly correlated with baseline pain characteristics, or parent or child pain catastrophizing. Levels of pain catastrophizing did not significantly differ by sex $(p>.05)$. Females reported significantly greater baseline pain interference than males $(p<.01)$. Higher baseline youth pain catastrophizing was associated with higher baseline youth pain intensity $(r=.46, p<.001)$, unpleasantness $(r=.63, p<.001)$, and interference $(r=.54, p<.001)$. Higher baseline parent pain catastrophizing was associated 
with higher baseline youth pain interference $(r=.25, p=.02)$. Tables 2 and 3 report the means and standard deviations of the baseline and daily variables. The zero-order correlations (i.e., correlations at the individual level) of the daily variables are reported in Table 4.

\section{Model Testing}

The standardized results of the 2-level path analyses are represented in Figures 1-4.

\section{Hypothesis 1}

We hypothesized that more negative parent mood and increased parent protective responses would be associated with increased youth pain intensity, interference, and unpleasantness on a daily basis. When parents reported more negative mood youth reported greater same-day pain unpleasantness $(\beta=-.13, p<.001)$ and pain intensity $(\beta=-.06, p<.05)$. When parents reported engaging in more protective responses, youth reported greater same-day pain unpleasantness $(\beta=.16, p<.01)$, interference $(\beta=.14, p<.001)$, and intensity $(\beta=.13, p<.05)$.

\section{Hypothesis 2}

We hypothesized that higher parent and youth pain catastrophizing assessed at baseline would predict stronger daily associations between parent protectiveness/mood and youth pain. When examining the daily associations between parent mood and youth pain experiences as moderated by youth and parent pain catastrophizing (Table 5), baseline youth pain catastrophizing had a significant negative direct effect on the daily association between parent mood and youth pain unpleasantness $(\beta=-.01, p<.01)$ and intensity $(\beta=-.01, p<.05)$. Thus, consistent with hypotheses, higher baseline youth pain catastrophizing predicted a stronger daily association between parent mood and youth pain unpleasantness and intensity. Inconsistent with hypotheses, youth pain catastrophizing did not moderate the association between parent mood and youth pain interference. Likewise, parent pain catastrophizing did not moderate the 
association between parent mood and youth pain experiences (i.e., pain intensity, interference or unpleasantness). Greater baseline youth pain catastrophizing was directly associated with higher levels of daily youth pain unpleasantness $(\beta=.04, p<.001)$, interference $(\beta=.44, p<.001)$, and intensity $(\beta=.08, p<.01)$. Counter to expectations, when examining the daily associations between parent protectiveness and youth pain experiences as moderated by parent and youth pain catastrophizing (Table 6), greater baseline parent pain catastrophizing was directly associated with a weaker daily association between parent protectiveness and youth pain interference $(\beta=-$ $.21, p<.05)$. Parent pain catastrophizing did not moderate the association between parent protectiveness and youth pain unpleasantness or intensity. Youth pain catastrophizing did not moderate the association between parent protectiveness and youth pain experience (i.e., pain intensity, interference, or unpleasantness). Greater baseline parent pain catastrophizing was directly associated with higher daily youth pain interference $(\beta=.27, p<.05)$.

\section{Discussion}

This study examined the moderating roles of parent and youth pain catastrophizing in the

daily associations between parent mood, parent protective responses, and youth pain experiences, in a sample of youth with idiopathic chronic pain. It extends previous research conducted in children with arthritis using daily diaries [7]. Our design, which used a micro-longitudinal, ecologically-valid approach, enabled investigation of the dynamic interplay between parental psychological and behavioural factors and youth chronic pain as they naturally unfolded in children's home environments and in reference to their specific chronic pain complaints. Findings revealed that more negative daily parent mood predicted higher youth pain unpleasantness and intensity. Increased parent protective responses predicted higher youth pain unpleasantness, pain interference, and pain intensity. Additionally, higher baseline youth pain 
catastrophizing predicted a stronger daily association between parent mood and youth pain unpleasantness and intensity. In contrast, higher baseline parent pain catastrophizing predicted a weaker daily association between parent protective responses and youth pain interference.

Similar to the findings of Connelly and colleagues [7], a substantial and non-trivial proportion of total variance of parent mood and protective reponses was due to within-person differences, demonstrating that parent mood and protective responses are dynamic and variable over time. This supports the importance of measuring parent mood and protective responses on a daily basis and suggests that context plays a role in how parents feel and respond to their child's pain on any given day. Measuring parent mood and responses in a static way will not capture this important variability. Alternative models were investigated in which youth pain influenced parent mood and protective responses. These models consistently fit the data worse than hypothesized models, suggesting that parent mood and protective responses more strongly influence youth pain responses each day, rather than youth pain complaints eliciting higher levels of parental protective responses and more negative mood. Findings demonstrate that, in addition to parent protective responses, parents' mood has a significant influence on their child's chronic pain. This underscores the importance of investigating parental psychological factors in examinations of youth chronic pain.

Our findings suggest that individual differences among parents and youth influence the previously described dyadic relationships. Our findings suggest that youth who catastrophize more about their pain are more vulnerable to the effects of parent mood on their pain. Thus, parent mood may be perceived as most threatening to, and may matter most for the pain experiences of, high catastrophizing youth. It is well established that parents influence children's pain. However, children's perceptions of their parents (e.g., mood) may also be an important 
factor of influence. Vervoort and colleagues investigated children's pain catastrophizing and their perceptions of parental positive (e.g., provision of emotional support) and negative (e.g., responding punitively) responses to pain [47]. Child pain catastrophizing was associated with child-reported parental positive and negative attention and this association was moderated by child attachment [47]. Specifically, in the context of an insecure attachment, higher child catastrophizing was associated with more child-reported negative parental responses [47]. In the context of a secure attachment, however, higher levels of pain catastrophizing were associated with child-reported positive parental responses [47]. This suggests that pain catastrophizing may enhance children's perceptions of parental responses to their pain, whether positive or negative, and emphasizes the importance of considering the quality of the parent-child relationship. Parental mood is likely salient information that may be enhanced by one's tendency to think catastrophically about pain. Children who catastrophize more about pain may be hypervigilant or have an attentional bias towards signals of low parental mood, which may signal additional threat to the child. In the current study, the manner in which parent mood was affectively communicated to, or interpreted by, the child (e.g., tone of interactions) is unknown. Nevertheless, our findings suggest that youth who catastrophize more about their pain may be more vulnerable to the effect of parent mood on their pain. Further, because daily child mood was not assessed, it is possible that parent and child mood influence each other in dynamic ways.

Counter to expectations, higher baseline parent pain catastrophizing predicted a weaker daily association between parent protective responses and youth pain interference. This suggests that parents who catastrophize more about their child's pain have children who are less vulnerable to the daily effects of parent protective responses on their pain, and there are other factors that may be influencing the strength of this relationship. Individual differences among 
parents (e.g., distress, catastrophizing) are likely to influence their attention to their child's pain as well as the impact of child pain expression on the parent [13]. Vervoort and colleagues' [49] affective-motivational model of interpersonal pain dynamics posits that differential affectivemotivational substrates (e.g., self- vs other-oriented motives and emotions) may underpin differential effects of parent behaviour on pain experiences through nonverbal features (e.g., vocal tone, facial expression) and flexibility (e.g., rigid focus on pain/nonpain goals). While speculative, it could be that protective responses have different effects on the individual child's pain experience depending on how they are communicated (e.g. facial expression, tone of voice) by a parent. Nevertheless, research is needed to further explore these findings in other samples and to further investigate the impact of affective-motivational factors (e.g., catastrophizing) on parent responses to their child's pain through self- vs other-oriented processes, including measuring non-verbal behaviours in these interactions that could influence how these relationships unfold.

Results should be interpreted in light of limitations. Data were collected from only one parent and the majority of parents were mothers (95\%). Given that within person variability in parent protective responses and mood were found, both parents are unlikely to respond in the same manner to their child's pain. One parents' response might buffer, or alternatively exacerbate, that of the other. Given that parental catastrophizing about their own pain has also been associated with protective parent responses [20], parent cognitions about their own pain is likely an important factor in these relationships. Similar to other studies of tertiary level pediatric chronic pain programs, our sample was predominantly white and of high socioeconomic status. Additionally, although use of daily diary questionnaires allowed for examination of these relationships in children's natural day-to-day lives, future research should 
utilize more detailed ecological momentary assessment methodology (i.e., self-reports several times a day). The use of real-time data capture reduces the effects of recall bias in pain reporting [43], but can present issues with feasibility and participant retention. Although our study measures have been used in daily diary formats, they were not validated for this purpose. Parents were also not prompted to complete the protectiveness measure if they reported their child experienced no pain that day, resulting in missing data. Future research could consider providing more general prompts about parent behaviour that are not dependent on whether or not they report their child experiencing pain. Like protectiveness, emerging research suggests that catastrophizing in the context of pediatric pain may also be dynamic [11]. Examination of state and trait catastrophizing constructs is an important direction of future research. As well, future research should consider using a broader measure to assess the complexity of parent daily mood. Finally, while significant moderation effects were found, several hypothesized models were not supported. Future research is needed to replicate our findings.

In conclusion, the current study contributes to an emerging body of literature pointing to the importance of parent psychological and behavioural factors in pediatric chronic pain. Teaching parents behavioural strategies to promote adaptive functioning of children is a critical component of cognitive behavioural therapy for pediatric chronic pain [12]. However, more recent approaches to the management of chronic pain also target parent distress [35]. This is important in light of emerging evidence showing the powerful influence of parental mental health on child pain and treatment response. This study has direct implications for clinical practice, highlighting the importance of addressing daily parent-youth interactions, as well as parent and youth cognitive-affective factors, in the assessment and treatment of pediatric chronic pain. Individual differences (e.g., catastrophizing) in parents and youth are one way to determine 
which families may benefit more from particular interventions. Indeed, these findings further support that youth with chronic pain and their parents are not a homogenous group. Depending on the cognitive-affective orientation of the parent and child, the impact of parent mood and protectiveness on child pain differs. As such, these findings suggest that it may be important to match different families to different interventions that focus more on parental behavior versus mental health.

Acknowledgments: This research was supported by funding from the Vi Riddell Pediatric Pain Initiative, the Alberta Children's Hospital Research Institute, and the Chronic Pain Network awarded to Dr. Noel. Alexandra Neville is supported by a Canadian Institutes of Health Research Doctoral Award and an Alberta Innovates Graduate Studentship. The authors have no conflicts of interest to disclose. 


\section{References}

[1] Affleck G, Zautra A, Tennen H, Armeli S. Multilevel daily process designs for consulting and clinical psychology: A preface for the perplexed. J Consult Clin Psych 1999;67(5):746-754.

[2] Aguilera A, Schueller SM, Leykin Y. Daily mood ratings via text message as a proxy for clinic based depression assessment. J Affect Disord 2015;175:471-474.

[3] Caes L, Vervoort T, Eccleston C, Vandenhende M, Goubert L. Parental catastrophizing about child's pain and its relationship with activity restriction: the mediating role of parental distress. Pain 2011;152(1):212-222.

[4] Castarlenas E, Jensen MP, von Baeyer CL, Miro J. Psychometric properties of the Numerical Rating Scale to assess self-reported pain intensity in children and adolescents: a systematic review. Clinical Journal of Pain 2017;33(4):376-383.

[5] Claar RL, Simons LE, Logan DE. Parental response to children's pain: the moderating impact of children's emotional distress on symptoms and disability. Pain 2008;138(1):172-179.

[6] Collins LM, Schafer JL, Kam CM. A comparison of inclusive and restrictive strategies in modern missing data procedures. Psychol Methods 2001;6(4):330-351.

[7] Connelly M, Bromberg MH, Anthony KK, Gil KM, Schanberg LE. Use of smartphones to prospectively evaluate predictors and outcomes of caregiver responses to pain in youth with chronic disease. Pain 2017;0(0):1-8.

[8] Craig KD. The social communication model of pain. Canadian Psychology 2009;50(1):22-32.

[9] Crombez G, Bijttebier P, Eccleston C, Mascagni T, Mertens G, Goubert L, Verstraeten K. The child version of the pain catastrophizing scale (PCS-C): a preliminary validation. Pain 2003;104(3):639-646.

[10] Duncan SC, Duncan TE, Strycker LA. Alcohol use from ages 9 to 16: A cohort-sequential latent growth model. Drug and Alcohol Dependence 2006;81:71-81.

[11] Durand H, Birnie KA, Noel M, Vervoort T, Goubert L, Boerner KE, Chambers CT, Caes L. State Versus Trait: Validating State Assessment of Child and Parental Catastrophic Thinking About Children's Acute Pain. J Pain 2017;18(4):385-395.

[12] Fisher E, Law E, Dudeney J, Palermo TM, Stewart G, Eccleston C. Psychological therapies for the management of chronic and recurrent pain in children and adolescents. Cochrane Database Syst Rev 2018;9:CD003968.

[13] Goubert L, Craig KD, Vervoort T, Morley S, Sullivan MJ, Williams ACC, Cano A, Crombez G. Facing others in pain: the effects of empathy. Pain 2005;118(3):285-288.

[14] Goubert L, Eccleston C, Vervoort T, Jordan A, Crombez G. Parental catastrophizing about their child's pain. The parent version of the Pain Catastrophizing Scale (PCS-P): a preliminary validation. Pain 2006;123(3):254-263.

[15] Guite JW, McCue RL, Sherker JL, Sherry DD, Rose JB. Relationships among pain, protective parental responses, and disability for adolescents with chronic musculoskeletal pain: the mediating role of pain catastrophizing. Clin J Pain 2011;27(9):775-781.

[16] Harris PA, Taylor R, Thielke R, Payne J, Gonzalez N, Conde JG. Research electronic data capture (REDCap)--a metadata-driven methodology and workflow process for providing translational research informatics support. J Biomed Inform 2009;42(2):377-381.

[17] Hox J. Multilevel analysis: Techniques and applications. New York, NY: Routledge, 2010. 
[18] Irwin DE, Stucky BD, Thissen D, Dewitt EM, Lai JS, Yeatts K, Varni JW, DeWalt DA. Sampling plan and patient characteristics of the PROMIS pediatrics large-scale survey. Qual Life Res 2010;19(4):585-594.

[19] King S, Chambers CT, Huguet A, MacNevin RC, McGrath PJ, Parker L, MacDonald AJ. The epidemiology of chronic pain in children and adolescents revisited: a systematic review. Pain 2011;152(12):2729-2738.

[20] Langer SL, Romano JM, Levy RL, Walker LS, Whitehead WE. Catastrophizing and parental response to child symptom complaints. Child Health Care 2009;38(3):169-184.

[21] Law EF, Fisher E, Howard WJ, Levy R, Ritterband L, Palermo TM. Longitudinal change in parent and child functioning after internet-delivered cognitive-behavioral therapy for chronic pain. Pain 2017;158(10):1992-2000.

[22] Lewandowski AS, Palermo TM, De la Motte S, Fu R. Temporal daily associations between pain and sleep in adolescents with chronic pain versus healthy adolescents. Pain 2010;151(1):220-225.

[23] Lleras C. Path Analysis. The Encyclopedia of Social Measurement. New York, NY: Academic Press, 2005.

[24] Logan DE, Scharff L. Relationships between family and parent characteristics and functional abilities in children with recurrent pain syndromes: an investigation of moderating effects on the pathway from pain to disability. J Pediatr Psychol 2005;30(8):698-707.

[25] Logan DE, Simons LE, Carpino EA. Too sick for school? Parent influences on school functioning among children with chronic pain. Pain 2012;153(2):437-443.

[26] Lynch-Jordan AM, Kashikar-Zuck S, Szabova A, Goldschneider KR. The interplay of parent and adolescent catastrophizing and its impact on adolescents' pain, functioning, and pain behavior. Clin J Pain 2013;29(8):681-688.

[27] Maas CJM, Hox JJ. Sufficient sample sizes for multilevel modeling. Methodology 2005;1(3):86-92.

[28] Marcoulides GA, Schumacker RE. New developments and techniques in structural equation modeling. Mahwah, NJ: Lawrence Erlbaum Associates 2009.

[29] McGrath PA. Pain in children: nature, assessment, and treatment. New York: Guildford Press, 1990.

[30] Muthen LK, Muthen BO. Mplus user's guide. Los Angeles, CA: Muthen \& Muthen 2012.

[31] Neville A, Jordan A, Beveridge JK, Pincus T, Noel M. Diagnostic uncertainty in youth with chronic pain and their parents. J Pain 2019.

[32] Noel M, Alberts N, Langer SL, Levy RL, Walker LS, Palermo TM. The sensitivity to change and responsiveness of the adult responses to children's symptoms in children and adolescents with chronic pain. J Pediatr Psychol 2016;41(3):350-362.

[33] Noel M, Palermo TM, Essner B, Zhou C, Levy RL, Langer SL, Sherman AL, Walker LS. A developmental analysis of the factorial validity of the parent-report version of the Adult Responses to Children's Symptoms in children versus adolescents with chronic pain or pain-related chronic illness. J Pain 2015;16(1):31-41.

[34] Palermo TM, Chambers CT. Parent and family factors in pediatric chronic pain and disability: an integrative approach. Pain 2005;119(1-3):1-4.

[35] Palermo TM, Law EF, Bromberg M, Fales J, Eccleston C, Wilson AC. Problem-solving skills training for parents of children with chronic pain: a pilot randomized controlled trial. Pain 2016;157(6):1213-1223. 
[36] Palermo TM, Valenzuela D, Stork PP. A randomized trial of electronic versus paper pain diaries in children: impact on compliance, accuracy, and acceptability. Pain 2004;107(3):213-219.

[37] Palermo TM, Witherspoon D, Valenzuela D, Drotar DD. Development and validation of the Child Activity Limitations Interview: a measure of pain-related functional impairment in school-age children and adolescents. Pain 2004;109(3):461-470.

[38] Pielech M, Ryan M, Logan D, Kaczynski K, White MT, Simons LE. Pain catastrophizing in children with chronic pain and their parents: proposed clinical reference points and reexamination of the Pain Catastrophizing Scale measure. Pain 2014;155(11):2360-2367.

[39] Poppert Cordts KM, Stone AL, Beveridge JK, Wilson AC, Noel M. The (parental) whole is greater than the sum of its parts: a multifactorial model of parent factors in pediatric chronic pain. J Pain 2019.

[40] Rabbitts JA, Groenewald CB, Tai GG, Palermo TM. Presurgical psychosocial predictors of acute postsurgical pain and quality of life in children undergoing major surgery. $J$ Pain 2015;16(3):226-234.

[41] Ross CK, Lavigne JV, Hayford JR, Berry SL, Sinacore JM, Pachman LM. Psychological factors affecting reported pain in juvenile rheumatoid arthritis. J Pediatr Psychol 1993;18(5):561-573.

[42] Shiffman S, Stone AA, Hufford MR. Ecological momentary assessment. Annu Rev Clin Psychol 2008;4:1-32.

[43] Stinson JN. Improving the assessment of pediatric chronic pain: harnessing the potential of electronic diaries. Pain Res Manag 2009;14(1):59-64.

[44] Van der Veek SMC, Derkx HHF, De Haan E, Benninga MA, Plak RD, Boer F. Do parents maintain or exacerbate pediatric functional abdominal pain? a systematic review and meta-analysis. J Health Psychol 2012;17(2):258-272.

[45] Van Slyke DA, Walker LS. Mothers' responses to children's pain. Clin J Pain 2006;22(4):387-391.

[46] Vervoort T, Caes L, Trost Z, Sullivan M, Vangronsveld K, Goubert L. Social modulation of facial pain display in high-catastrophizing children: an observational study in schoolchildren and their parents. Pain 2011;152(7):1591-1599.

[47] Vervoort T, Goubert L, Crombez G. Parental responses to pain in high catastrophizing children: the moderating effect of child attachment. J Pain 2010;11(8):755-763.

[48] Vervoort T, Goubert L, Eccleston C, Bijttebier P, Crombez G. Catastrophic thinking about pain is independently associated with pain severity, disability, and somatic complaints in school children and children with chronic pain. J Pediatr Psychol 2006;31(7):674-683.

[49] Vervoort T, Trost Z. Examining affective-motivational dynamics and behavioral implications within the interpersonal context of pain. J Pain 2017;18(10):1174-1183.

[50] von Baeyer CL, Spagrud LJ, McCormick JC, Choo E, Neville K, Connelly MA. Three new datasets supporting use of the Numerical Rating Scale (NRS-11) for children's selfreports of pain intensity. Pain 2009;143(3):223-227.

[51] Zhang Z, Zyphur MJ, Preacher KJ. Testing multilevel mediation using hierarchical linear models problems and solutions. Organizational Research Methods 2009;12(4):695-719. 
Figure 1. Standardized results of the 2-level path analysis used to test the daily association between youth pain experiences and parent mood as predicted by youth pain catastrophizing. Figure 2. Standardized results of the 2-level path analysis used to test the daily association between youth pain experiences and parent mood as predicted by parent pain catastrophizing. Figure 3. Standardized results of the 2-level path analysis used to test the daily association between youth pain experiences and parent protectiveness as predicted by youth pain catastrophizing.

Figure 4. Standardized results of the 2-level path analysis used to test the daily association between youth pain experiences and parent protectiveness as predicted by parent pain catastrophizing. 


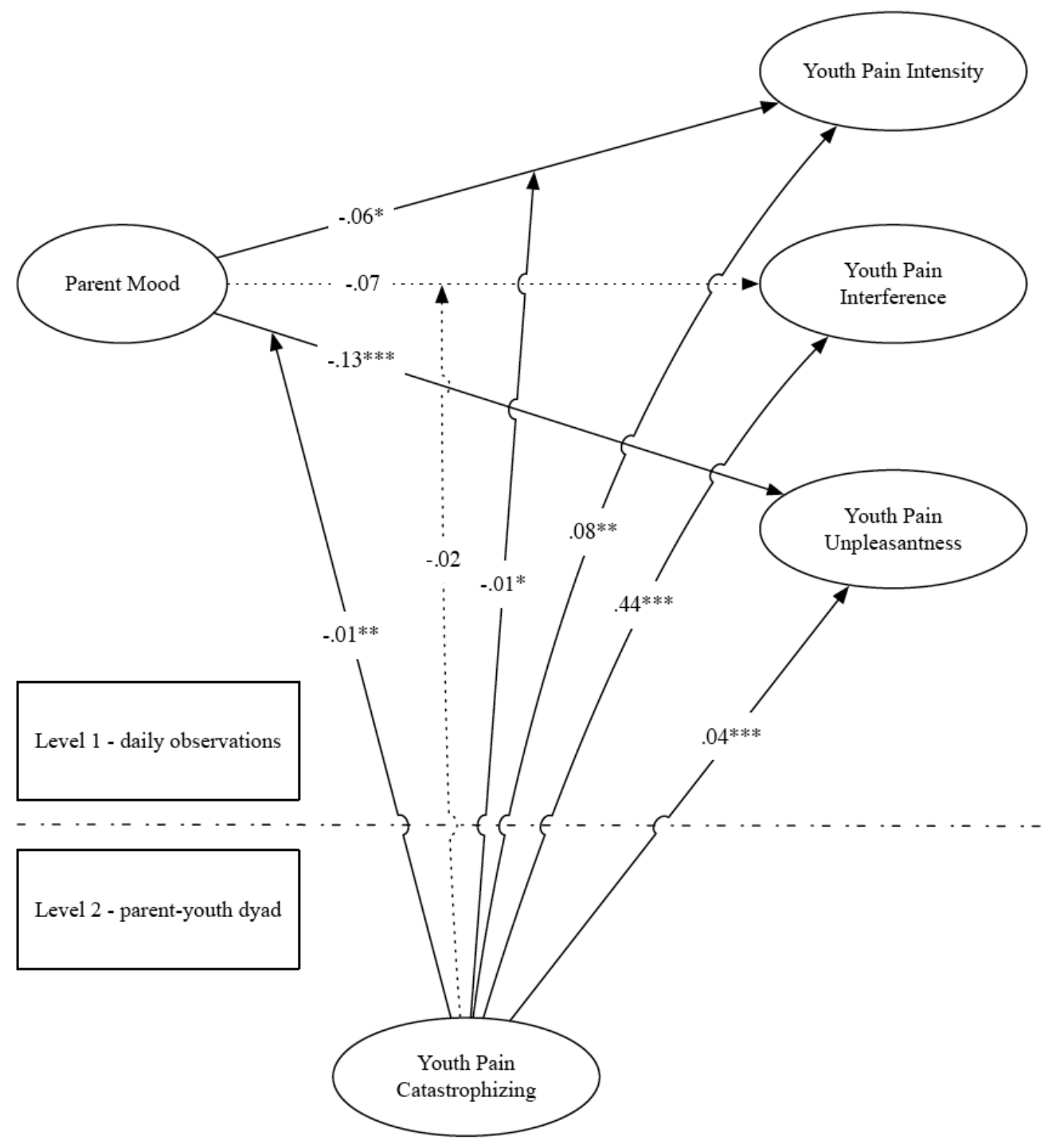




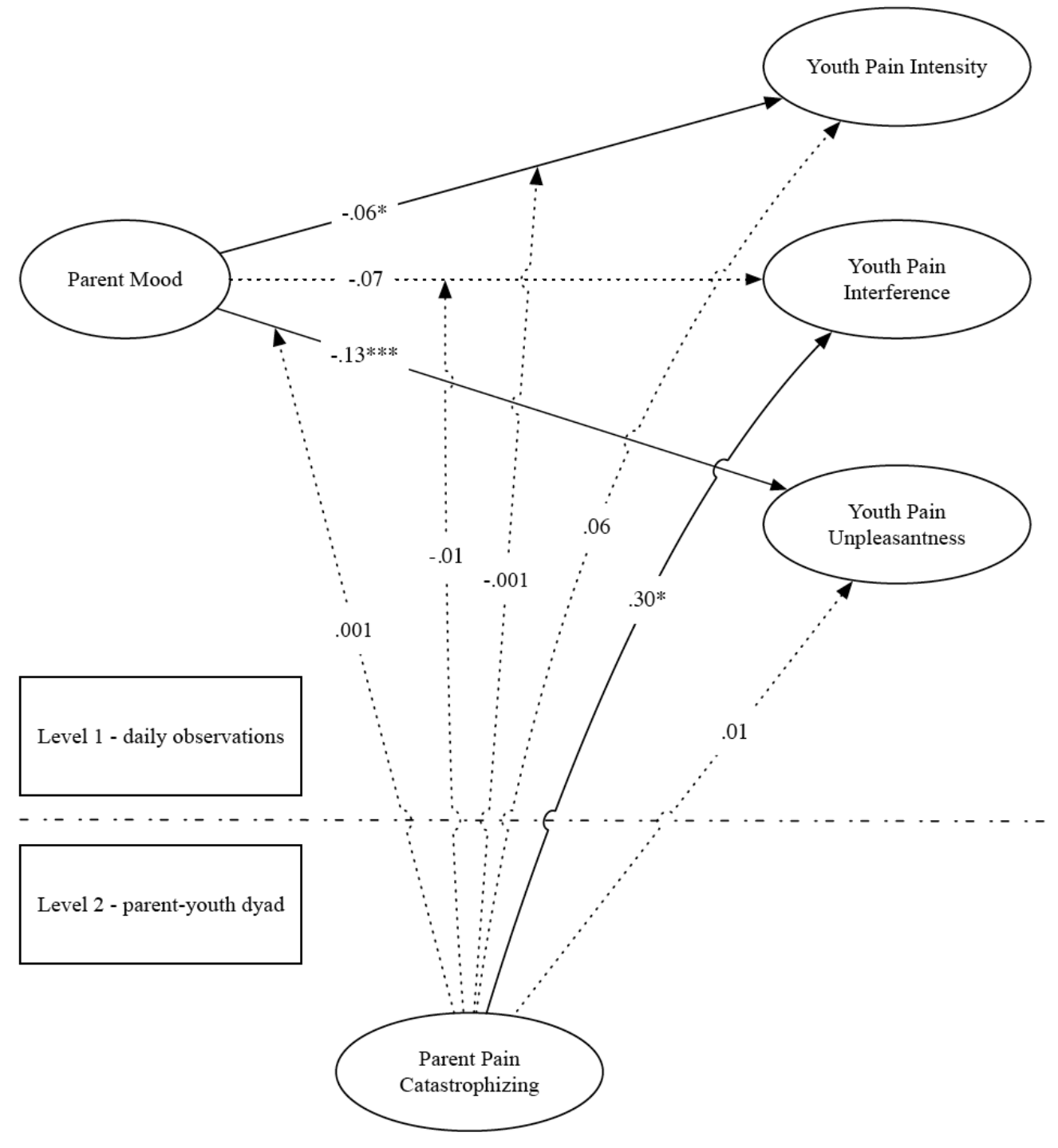




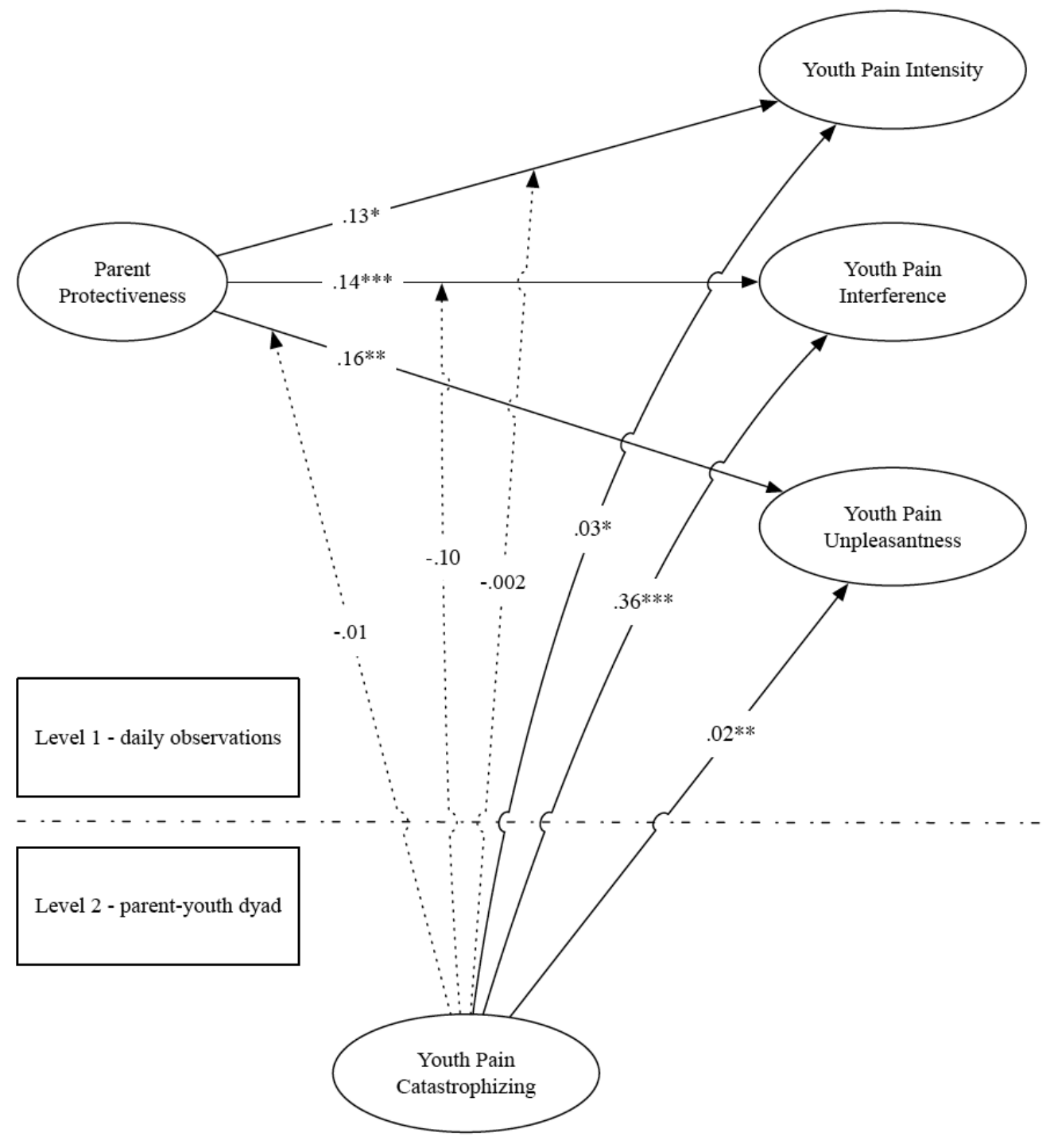




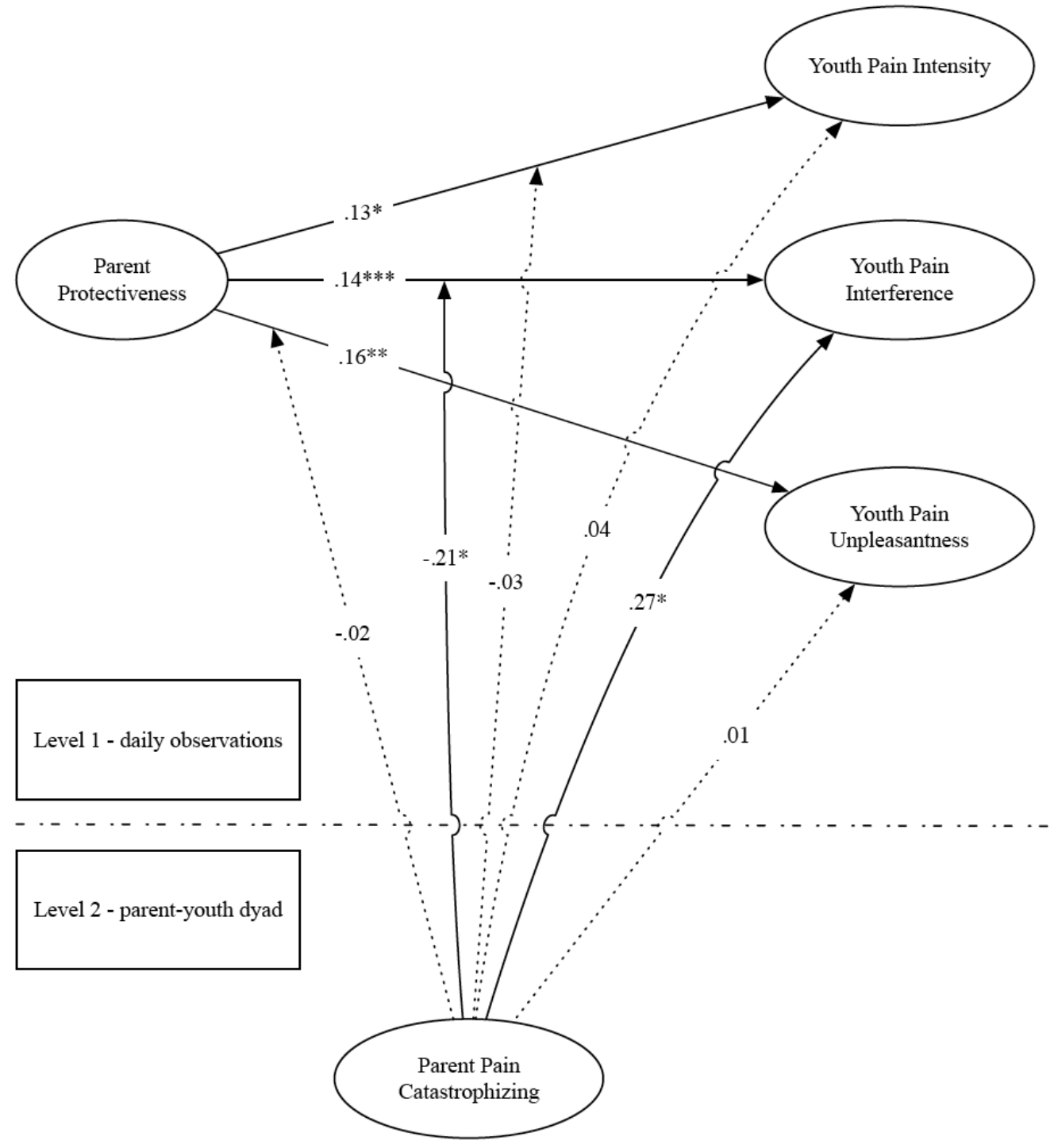


Table 1

Socio-Demographic Characteristics of the Sample

Socio-Demographics N=95

Youth mean age (SD), years

$14.08(2.32)$

Youth sex (\% female)

71.6

Parent sex (\% female)

94.5

Relationship to the youth (\%)

Biological parent

99.0

Relative

1.0

Youth ethnicity (\%)

White (Caucasian)

85.3

Two or more ethnicities

3.2

Latin American

3.2

Other

4.1

Do not want to answer

4.2

Household income (\%)

$$
<\$ 10,000-\$ 29,999
$$

$\$ 30,000-\$ 59,999$

10.5

$\$ 60,000-\$ 89,999$

10.5

More than $\$ 90,000$

64.4

Do not want to answer

9.3

Mean school days missed in the past $3 \quad 6.47$ (8.44) months (SD) 
Table 2

Descriptive Statistics for Youth and Parent Baseline Variables

\begin{tabular}{lcc}
\hline Variable & $\mathrm{N}$ & $M(S D)$ \\
\hline Parent Catastrophizing, (PCS-P) total & 88 & $15.05(9.22)$ \\
Youth Catastrophizing, (PCS-C), total & 91 & $20.02(12.53)$ \\
Youth pain intensity, total & 89 & $5.62(1.87)$ \\
Youth pain unpleasantness, total & 89 & $2.03(.95)$ \\
Youth pain interference (PROMIS), T- & 89 & $56.23(9.49)$ \\
score & & \\
\hline
\end{tabular}

Note. PCS-P = Pain Catastrophizing Scale-Parent version; PCS-C = Pain Catastrophizing ScaleChild version; PROMIS = Patient-Reported Outcomes Measurement Information System; PCS-P and PCS-C possible total score range $=0-52$; Youth pain intensity possible total score range $=0$ 10; Youth pain unpleasantness possible total score range $=0-4$; Youth pain interference possible T-score range $=36.7-74$.

Table 3

Descriptive Statistics for Youth and Parent Daily Variables

\begin{tabular}{lcc}
\hline Variable & $\mathrm{N}$ & $M(S D)$ \\
\hline Parent Mood & 644 & $6.94(2.18)$ \\
& & $6.72-7.09$ \\
Parent protective responses (ARCS protect & 483 & $.47(.68)$ \\
scale), mean & & $.36-.54$ \\
Youth pain intensity, total & 630 & $4.77(2.80)$ \\
& & $4.64-4.79$ \\
Youth pain unpleasantness, total & 543 & $1.82(1.03)$ \\
& & $1.66-1.97$ \\
Youth pain interference (PROMIS), T- & 544 & $51.90(10.39)$ \\
score & & $50.42-52.76$ \\
\hline
\end{tabular}

Note. ARCS = Adult Responses to Children's Symptoms; PROMIS = Patient-Reported Outcomes Measurement Information System. N = number of observations. Parent mood possible 
score range $=0-10$; Parent protective responses possible total score range $=0-4$; Youth pain intensity possible total score range $=0-10$; Youth pain unpleasantness possible total score range $=0-4$; Youth pain interference possible T-score range $=36.7-74$.

Table 4

Zero-order and Person-centered Correlations Among Variables of Interest for Daily Data

\begin{tabular}{lccccc}
\hline Variable & 1 & 2 & 3 & 4 & 5 \\
\hline 1. Parent mood & - & -.10 & -.08 & -.03 & -.02 \\
2. Parent protective responses (ARCS & $-.15^{* *}$ & - & -.01 & .17 & $.27^{*}$ \\
$\quad$ protect scale), mean & & & & & \\
3. Youth pain intensity, total & $-.08^{*}$ & $.12^{*}$ & - & $.63^{* * *}$ & $.51^{* * *}$ \\
4. Youth pain unpleasantness, total & -.07 & $.21^{* * *}$ & $.70^{* * *}$ & - & $.61^{* * *}$ \\
5. Youth pain interference & -.01 & $.29^{* * *}$ & $.51^{* * *}$ & $.59^{* * *}$ & - \\
(PROMIS), T-score & & & & &
\end{tabular}

Note. ${ }^{*} p<.05 ;{ }^{* *} p<.01,{ }^{* * *} p<.001$. Zero-order (between-person; $\mathrm{N}=95$ ) correlations are presented above the diagonal, whereas person-centered (within-person; $N=650$ ) correlations are presented below the diagonal. ARCS $=$ Adult Responses to Children's Symptoms; PROMIS = Patient-Reported Outcomes Measurement Information System.

Table 5

Sequence of Effects Analyzed to Test Daily Associations Between Youth Pain Experiences and Parent Mood as Predicted by Youth and Parent Pain Catastrophizing

\begin{tabular}{lccc}
\hline Within-Dyad Effects & $\begin{array}{c}\text { Point } \\
\text { estimate }\end{array}$ & $S E$ & $p$-value \\
\hline Parent Mood $\rightarrow$ Youth Pain Intensity & -.061 & .043 & .030 \\
Parent Mood $\rightarrow$ Youth Pain Interference & -.069 & .047 & .080 \\
Parent Mood $\rightarrow$ Youth Pain Unpleasantness & -.128 & .047 & $<.001$ \\
\hline Cross-Level Effects & Point & $S E$ & $p$-value \\
& estimate & & \\
\hline
\end{tabular}




\begin{tabular}{|c|c|c|c|}
\hline $\begin{array}{l}\text { Youth Pain Catastrophizing } \rightarrow \text { Youth Pain } \\
\text { Intensity }\end{array}$ & .084 & .031 & .001 \\
\hline $\begin{array}{l}\text { Youth Pain Catastrophizing } \rightarrow \text { Youth Pain } \\
\text { Interference }\end{array}$ & .439 & .113 & $<.001$ \\
\hline $\begin{array}{l}\text { Youth Pain Catastrophizing } \rightarrow \text { Youth Pain } \\
\text { Unpleasantness }\end{array}$ & .043 & .013 & $<.001$ \\
\hline $\begin{array}{l}\text { Youth Pain Catastrophizing x Parent Mood } \\
\rightarrow \text { Youth Pain Intensity }\end{array}$ & -.006 & .003 & .025 \\
\hline $\begin{array}{l}\text { Youth Pain Catastrophizing x Parent Mood } \\
\rightarrow \text { Youth Pain Interference }\end{array}$ & -.020 & .013 & .064 \\
\hline $\begin{array}{l}\text { Youth Pain Catastrophizing x Parent Mood } \\
\rightarrow \text { Youth Pain Unpleasantness }\end{array}$ & -.005 & .002 & .005 \\
\hline $\begin{array}{l}\text { Parent Pain Catastrophizing } \rightarrow \text { Youth Pain } \\
\text { Intensity }\end{array}$ & .055 & .046 & .096 \\
\hline $\begin{array}{l}\text { Parent Pain Catastrophizing } \rightarrow \text { Youth Pain } \\
\text { Interference }\end{array}$ & .302 & .180 & .045 \\
\hline $\begin{array}{l}\text { Parent Pain Catastrophizing } \rightarrow \text { Youth Pain } \\
\text { Unpleasantness }\end{array}$ & .010 & .023 & .359 \\
\hline $\begin{array}{l}\text { Parent Pain Catastrophizing x Parent Mood } \\
\rightarrow \text { Youth Pain Intensity }\end{array}$ & -.001 & .006 & .457 \\
\hline $\begin{array}{l}\text { Parent Pain Catastrophizing x Parent Mood } \\
\rightarrow \text { Youth Pain Interference }\end{array}$ & -.013 & .021 & .249 \\
\hline $\begin{array}{l}\text { Parent Pain Catastrophizing x Parent Mood } \\
\rightarrow \text { Youth Pain Unpleasantness }\end{array}$ & .001 & .003 & .459 \\
\hline
\end{tabular}

Table 6

Sequence of Effects Analyzed to Test Daily Associations Between Youth Pain Experiences and Parent Protectiveness as Predicted by Youth and Parent Pain Catastrophizing

\begin{tabular}{lccc}
\hline Within-Dyad Effects & $\begin{array}{c}\text { Point } \\
\text { estimate }\end{array}$ & SE-value \\
\hline
\end{tabular}




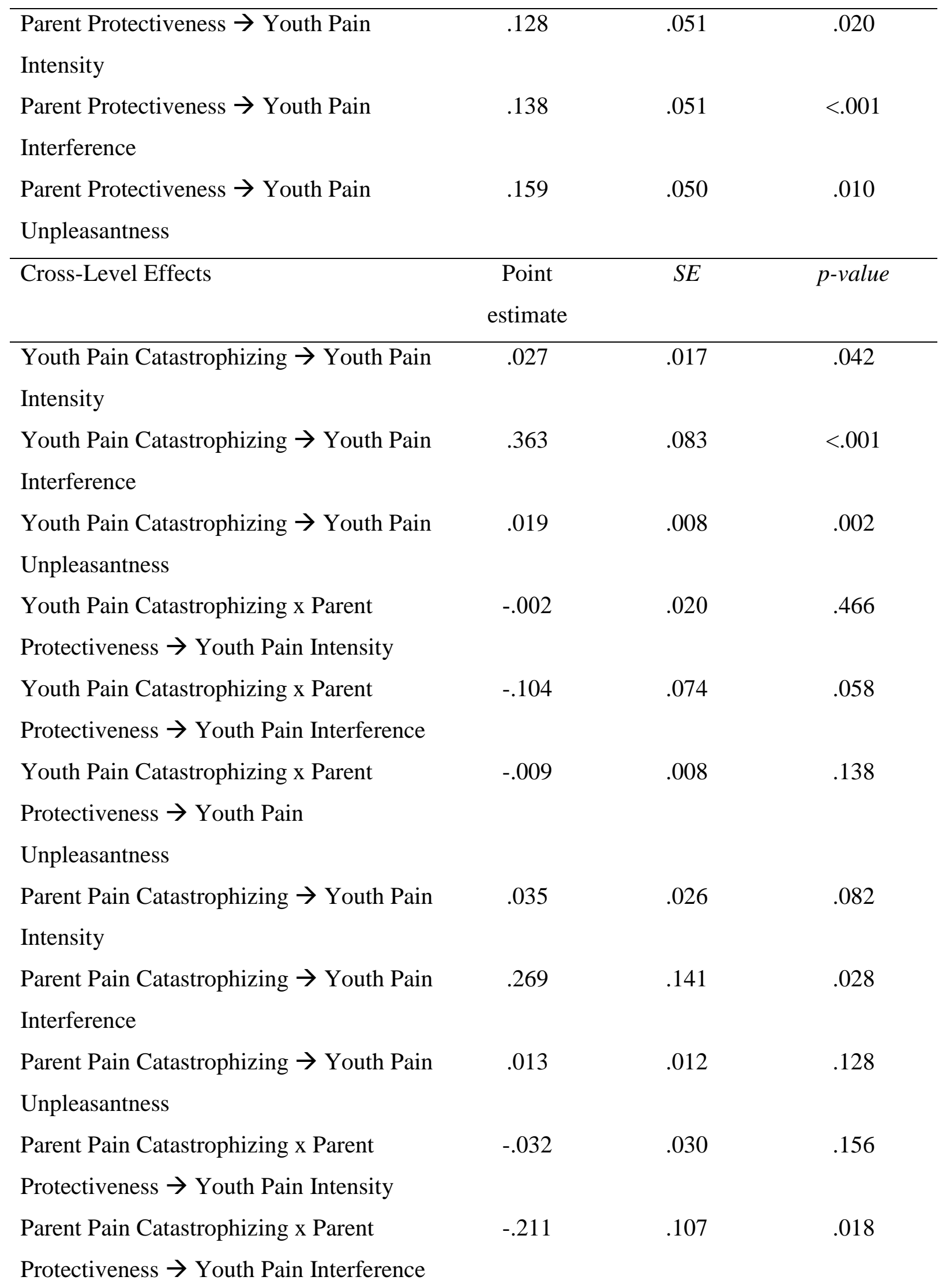


Parent Pain Catastrophizing x Parent

$-.015$

.011

.058

Protectiveness $\rightarrow$ Youth Pain

Unpleasantness 